\title{
Slowing of EEG background activity in Parkinson's and Alzheimer's disease with early cognitive dysfunction
}

\section{Nina Benz ${ }^{1 \dagger}$, Florian Hatz ${ }^{1 \dagger}$, Habib Bousleiman ${ }^{1,2}$, Michael M. Ehrensperger ${ }^{3}$, Ute Gschwandtner ${ }^{1}$, Martin Hardmeier ${ }^{1}$, Stephan Ruegg ${ }^{1}$, Christian Schindler ${ }^{2}$, Ronan Zimmermann ${ }^{1}$, Andreas Urs Monsch ${ }^{3}$ and Peter Fuhr ${ }^{1 *}$}

1 Department of Neurology, Hospitals of University of Basel, Basel, Switzerland

${ }^{2}$ Swiss Tropical and Public Health Institute, University of Basel, Basel, Switzerland

${ }^{3}$ Memory Clinic, University Center for Medicine of Aging Basel, Felix Platter Hospital, Basel, Switzerland

Edited by:

P. Hemachandra Reddy, Texas Tech

University, USA

\section{Reviewed by:}

Samba Reddy, Texas A\&M University

Health Science Center, USA

Koteswara Rao Valasani, The

University of Kansas, USA

\section{${ }^{*}$ Correspondence:}

Peter Fuhr, Department of Neurology, University Hospital Basel,

Petersgraben 4, Basel 4031,

Switzerland

e-mail: peter.fuhr@usb.ch

${ }^{\dagger}$ Nina Benz and Florian Hatz have contributed equally to this work.
Background: Slowing of the electroencephalogram (EEG) is frequent in Parkinson's (PD) and Alzheimer's disease (AD) and correlates with cognitive decline. As overlap pathology plays a role in the pathogenesis of dementia, it is likely that demented patients in PD show similar physiological alterations as in AD.

Objective:To analyze distinctive quantitative EEG characteristics in early cognitive dysfunction in PD and AD.

Methods: Forty patients (20 PD- and 20 AD patients with early cognitive impairment) and 20 normal controls (NC) were matched for gender, age, and education. Resting state EEG was recorded from 256 electrodes. Relative power spectra, median frequency $(4-14 \mathrm{~Hz}$ ), and neuropsychological outcome were compared between groups.

Results: Relative theta power in left temporal region and median frequency separated the three groups significantly $(p=0.002$ and $p<0.001)$. Relative theta power was increased and median frequency reduced in patients with both diseases compared to NC. Median frequency was higher in $A D$ than in PD and classified groups significantly $(p=0.02)$.

Conclusion: Increase of theta power in the left temporal region and a reduction of median frequency were associated with presence of $A D$ or PD. PD patients are characterized by a pronounced slowing as compared to AD patients. Therefore, in both disorders EEG slowing might be a useful biomarker for beginning cognitive decline.

Keywords: Parkinson's disease, Alzheimer's disease, mild cognitive impairment, dementia, quantitative electroencephalography, neuropsychology

\section{INTRODUCTION}

Mild cognitive impairment (MCI) is a prodromal syndrome of neurodegenerative dementia without significant impairment in activities of daily living (ADL); however, it is unspecific as it can be caused by various pathologies (Winblad et al., 2004), and a considerable part of MCI patients remain stable or improve over time (Ritchie et al., 2001). Diagnostic criteria for MCI due to Parkinson's disease (PD-MCI) and Alzheimer's disease (AD-MCI) were established (Albert et al., 2011; Litvan et al., 2012). The progression rate in PD-MCI to PD dementia (PDD) is approximately $60 \%$ over 4 years (Janvin et al., 2006); the rate of conversion to AD in MCI patients varies depending on study design and definition of MCI, though maximally one to two fifths of MCI patients with amnestic impairments at baseline progress to dementia within 2-3 years of follow-up (Schmidtke and Hermeneit, 2008; Duara et al., 2011). However, novel treatment strategies require initiation of treatment at the earliest possible time (Panza et al., 2012), and, therefore, the corroboration of the diagnosis and the identification of the cause of MCI is very important.
Quantitative electroencephalography (qEEG) has increasingly been used to characterize cognitive impairment in different disorders (Fonseca et al., 2009; Roh et al., 2011). The eyes closed resting state qEEG of patients suffering from dementia due to $\mathrm{AD}$ is characterized by a shift to lower frequencies (Penttilä et al., 1985; Duffy et al., 1995; Bennys et al., 2001; Czigler et al., 2008). The same observation is reported in PD patients with cognitive decline (Caviness et al., 2007; Fonseca et al., 2009; Bousleiman et al., 2014). In contrast to AD, slowing of electroencephalogram (EEG) can already be found in de novo PD patients without any cognitive deficits (Stoffers et al., 2007). Comparison of $\mathrm{AD}$ and PDD patients with a similar degree of overt dementia showed more pronounced EEG slowing in PDD (Babiloni et al., 2011; Fonseca et al., 2013). However, it is unknown whether qEEG measures reliably discriminate between the two diseases at the beginning of the dementing process or whether they simply correlate with the extent of cognitive decline. Thus, the present study aims at characterizing $\mathrm{qEEG}$ parameters in PD-MCI and AD-MCI. 


\section{MATERIALS AND METHODS PATIENTS}

Twenty patients with PD and cognitive decline (see Table 1) were recruited from the outpatient clinic for movement disorders of the University Hospital of Basel. PD was diagnosed according to UK Parkinson's disease brain bank criteria. The diagnosis of PD-MCI $(N=15)$ was based on Litvan et al. (2012). Diagnosis of "probable PDD” ( $N=5$ ) was made according to Emre et al. (2007), p. 007. All PD patients were treated with dopaminergic drugs [median levodopa-equivalent dose (LED) $=829 \mathrm{mg}$; range $188-3044 \mathrm{mg}$ ].

Thirty-seven outpatients (Table 1) with either amnestic MCI (AD-MCI, $N=12$ ) or mild dementia due to probable $\mathrm{AD}(N=8)$ were recruited from the Memory Clinic, University Center for Medicine of Aging, Basel. Thereof 20 patients were matched to the PD group for gender, age, and education. MCI due to probable AD was diagnosed according to Winblad et al. (2004). Dementia due to probable $\mathrm{AD}$ was diagnosed according to McKhann et al. (1984).

Exclusion criteria consisted of MMSE score (Folstein et al., $1975)<24 / 30$, significant psychiatric or organic brain disorders other than $\mathrm{PD}$ or $\mathrm{AD}$, any other severe illness, and drug treatment influencing EEG recordings (antiepileptic or antipsychotic drugs).

Twenty normal controls (NC) were matched to both patient groups according to gender, age, and education (Table 1). Inclusion criteria were a subjective report of good health and a neuropsychological examination within normal limits. Exclusion criteria were a past and/or current diagnosis of any major brain disorder, alcoholism, psychiatric disorder, general anesthesia within the last 3 months and cognitive problems. To compare global cognitive function between both patient groups, we chose a combination of the MMSE and the clock drawing test (CDT) (Thalmann et al., 2002). The study protocol was approved by the local ethics committee. Written informed consent was provided by all participants.

\section{NEUROPSYCHOLOGY}

Patients were examined with a comprehensive battery of neuropsychological tests [see Hatz et al. (2013) for details]. Raw scores of tests were transformed into demographically (age, gender, and education) adjusted $z$-scores (Berres et al., 2000). Cognitive performance was judged to be impaired when $z$-scores were less than -1.28 , i.e., below the 10 th percentile.

\section{EEG RECORDING}

Electroencephalogram was recorded with a 256-channel EEG System (Netstation 300, EGI, Inc., Eugene, OR 97403, USA; DCamplifier; sampling rate: $1000 \mathrm{~Hz}$; high-pass filter: $0.01 \mathrm{~Hz}$; vertexreference, impedance $\leq 40 \mathrm{k} \Omega$ ). They were instructed to relax, but to stay awake and to minimize eye and body movements. A continuous EEG with closed eyes was recorded for $12 \mathrm{~min}$. During data acquisition, a subset of electrodes was monitored online by a technician to check for vigilance and artifacts. For patients taking benzodiazepines for sleep deprivation (one patient per group), medication was discontinued before EEG recording for at least $48 \mathrm{~h}$. Only benzodiazepines with short half-life were allowed. One patient of the PD group was taking low-dose quetiapine for sleep deprivation, three patients were taking acetylcholinesterase inhibitors.

\section{PROCESSING OF EEG DATA}

Two minutes of EEG data (single segments of at least $40 \mathrm{~s}$ ) without artifacts or signs of sleep and drowsiness were visually selected, filtered $(0.5-70 \mathrm{~Hz}, 2400$ order least-squares filter) and downsampled $(500 \mathrm{~Hz})$. Data from 214 electrodes (excluding cheek and neck electrodes) were subjected to automated artifact detection (Hatz et al., 2014). Resulting EEG data were re-referenced to average reference and bad channels were interpolated with the spherical spline method. Power spectra were calculated from epochs of $4 \mathrm{~s}$ duration (Welch's method, spectral resolution $0.25 \mathrm{~Hz}$ ) using

Table 1 | Demographic characteristics and medications

\begin{tabular}{|c|c|c|c|c|c|}
\hline & NC & $\mathbf{A D}^{\mathrm{a}}$ & $\mathbf{P D}^{\mathbf{a}}$ & $p$-Value ${ }^{a}$ & Sub-group comparisons ${ }^{b}$ \\
\hline Age (years) & $73.5(67-83)$ & $73.5(57-87)$ & $74(60-84)$ & 0.77 & \\
\hline Education (years) & $13.5(10-19)$ & $14(8-20)$ & $15.5(8-20)$ & 0.60 & \\
\hline Gender (F/M) & $11 / 9$ & $10 / 10$ & $5 / 15$ & 0.12 & \\
\hline MMSE & $29(28-30)$ & $28(24-30)$ & $29(24-30)$ & $0.02^{*}$ & $N C>A D^{*}, N C>P D^{*}, A D=P D$ \\
\hline MMSE and CDT & $9(7-9)$ & $9(5-9)$ & $8.5(4-9)$ & 0.34 & \\
\hline I-DOPA & - & - & $18 / 20$ & & \\
\hline DOPA-agonists & - & - & $13 / 20$ & & \\
\hline MAO-inhibitors & - & - & $6 / 20$ & & \\
\hline Amantadine & - & - & $2 / 20$ & & \\
\hline COMT-inhibitor & - & - & $2 / 20$ & & \\
\hline AChE-inhibitors & - & $1 / 20$ & $2 / 20$ & & \\
\hline Antidepressants & - & $3 / 20$ & $4 / 20$ & & \\
\hline Neuroleptics & - & - & $1 / 20$ & & \\
\hline Benzodiazepines & $1 / 20$ & $1 / 20$ & $1 / 20$ & & \\
\hline
\end{tabular}

${ }^{a}$ p-Values for ANOVA, Kruskal-Wallis test.

${ }^{b}$ Mann-Whitney $U$ test.

${ }^{*} p<0.05, "=$ " no significant difference. 
a $80 \%$ Hanning window. The relative power for each frequency band was computed as the ratio between the absolute bandpower and the bandpower from 1 to $30 \mathrm{~Hz}$. Relative power in the delta- $(1-4 \mathrm{~Hz})$, theta- $(4-8 \mathrm{~Hz})$, alpha1- $(8-10 \mathrm{~Hz})$, alpha2$(10-13 \mathrm{~Hz})$, and beta- $(13-30 \mathrm{~Hz})$ bands were logit-transformed $[t(x)=\log (x /(1-x)]$ to achieve an approximate normal distribution (Gasser et al., 1982). Global band powers (average over all 214 electrodes) and regional band powers were computed. For regional analyses, electrodes were grouped into 10 regions of interest (ROI) corresponding to the frontal, central, temporal, parietal, and occipital areas bilaterally (Stoffers et al., 2007). Median frequency was calculated in a spectral window between 4 and $14 \mathrm{~Hz}$ at occipital electrodes. For calculation of the median frequency, a "center of gravity" approach was chosen, taking into account all spectra generated for a single subject.

\section{STATISTICS}

Demographic characteristics were compared between groups using non-parametric tests. EEG variables and results of neuropsychological tests were compared between the three groups using ANOVA. Subsequently, post hoc $t$-tests between sub-groups were applied. In case of regional EEG power analysis, permutation tests (statistics: ANOVA, $t$-test, number of 10,000 permutations) were used (Nichols and Holmes, 2002). A logistic regression analysis with backwards elimination to classify both groups was performed using the significant EEG measures from permutation tests as independent variables. Age, education, and gender served as covariates. Subsequently, a receiver-operatorcharacteristic (ROC) analysis was performed. Results with $p$ values $<0.05$ were considered significant. Comparison of demographic characteristics, global relative band power, neuropsychological results between groups and regression, as well as ROC analysis were done using $\mathrm{R}^{\circledR}$. Frequency analysis, ANOVA’s, $t$-tests, and permutation tests were performed with Matlab ${ }^{\circledR}$.

\section{RESULTS}

\section{DEMOGRAPHICS}

No significant differences between the patient groups regarding age, education, the combined MMSE/CDT, and gender were found (Kruskal-Wallis test, see Table 1). MMSE scores of both patient groups were similar and significantly smaller than those of the NC group $(p=0.04)$.

\section{NEUROPSYCHOLOGY}

Table 2 gives results of group- and sub-group comparisons. Subgroup comparison found differences between $\mathrm{PD}$ and $\mathrm{AD}$ patients in alertness/reaction time and divided attention/errors and in verbal memory (encoding, recall, and recognition).

\section{QUANTITATIVE EEG}

Global relative theta and global relative alpha2 power differed between the three groups. In sub-group comparison, NC had lower theta power compared PD and tended to lower theta power compared to $\mathrm{AD}$. $\mathrm{AD}$ tended to have lower global theta with respect to $\mathrm{PD}$, which had lower power in the alpha2 band compared to NC. Detailed results are given in Table 3.

Regional analysis of relative power data revealed group and sub-group differences in the theta- and alpha2 bands as depicted in Figure 1. In both patient groups, the most significant differences as compared to NC were found in the left temporal region.

Occipital median frequency differed significantly between groups with the following pattern found in the post hoc analysis: $\mathrm{NC}>\mathrm{AD}(p<0.05), \mathrm{NC}>\mathrm{PD}(p<0.001)$, and $\mathrm{AD}>\mathrm{PD}$ $(p<0.05)$.

Table 2 | Results of the neuropsychological assessments [age-, gender, and education corrected z-values (Berres et al., 2000)].

\begin{tabular}{|c|c|c|c|c|c|}
\hline & NC & $\mathbf{A D}^{\mathrm{a}}$ & $\mathbf{P D}^{\mathbf{a}}$ & $p$-Value ${ }^{a}$ & Sub-group comparisons ${ }^{b}$ \\
\hline Alertness & $-0.2(-1.8$ to 0.7$)$ & $-0.3(-1.8$ to 2.3$)$ & $0.1(-2.1$ to 2.1$)$ & 0.14 & \\
\hline Alertness RT & $0.3(-1.5$ to 2.3$)$ & $-0.1(-2.3$ to 2.8$)$ & $-1.1(-2.1$ to 0.5$)$ & 0.004 & $N C=A D, N C>P D^{* * *}, A D>P D^{*}$ \\
\hline Divided attention: errors & $0.2(-1.9$ to 2.3$)$ & $0.2(-1.2$ to 2.3$)$ & $-1.5(-2.1$ to 2.3$)$ & 0.01 & $N C=A D, N C>P D^{*}, A D>P D^{* *}$ \\
\hline TMT-A & $0.4(-1.3$ to 3.5$)$ & $0(-2.6$ to 3.5$)$ & $-0.3(-3$ to 1.1$)$ & 0.06 & \\
\hline Corsi blocks fw & $0(-1.2$ to 1.2$)$ & $0(-1.5$ to 1.8$)$ & $-0.6(-1.8$ to 1.2$)$ & 0.32 & \\
\hline Digit span fw & $0.1(-2.9$ to 1.8$)$ & $-0.5(-2$ to 2.1$)$ & $0.2(-1.1$ to 3$)$ & 0.10 & \\
\hline Corsi blocks bw & $0.5(-0.8$ to 1.9$)$ & $-0.4(-3.5$ to 1.2$)$ & $-0.1(-2.1$ to 1.5$)$ & 0.01 & $N C>A D^{* *}, N C=P D, A D=P D$ \\
\hline Digit span bw & $0.3(-1.7$ to 2.3$)$ & $-0.5(-1.7$ to 2.9$)$ & $0(-1.1$ to 2.3$)$ & 0.41 & \\
\hline Figures fluency & $-0.1(-2$ to 2$)$ & $-1(-3.7$ to 0.7$)$ & $-0.8(-1.9$ to 1.2$)$ & 0.01 & $N C>A D^{* *}, N C>P D^{*}, A D=P D$ \\
\hline Phonemic fluency & $0(-1.1$ to 2.6$)$ & $-0.4(-2.7$ to 1.2$)$ & $-0.2(-3.3$ to 2$)$ & 0.23 & \\
\hline Semantic fluency & $0.3(-2.3$ to 2$)$ & $-0.9(-2.5$ to 0.7$)$ & $-0.5(-1.8$ to 0.8$)$ & 0.002 & $N C>A D^{* *}, N C>P D^{*}, A D=P D$ \\
\hline Boston naming test & $-0.4(-1.9$ to 1.7$)$ & $-0.4(-2.3$ to 1.3$)$ & $-0.6(-3.3$ to 1.3$)$ & 0.20 & \\
\hline Encoding & $-0.1(-1.7$ to 1.8$)$ & $-2(-3.8$ to -0.7$)$ & $-1.3(-3.7$ to 0.2$)$ & $<0.001$ & $\mathrm{NC}>\mathrm{AD}^{* * *}, \mathrm{NC}>\mathrm{PD}^{* * *}, \mathrm{PD}>\mathrm{AD}^{* *}$ \\
\hline Recall & $0.3(-2.1$ to 1.4$)$ & $-2.5(-4$ to -0.3$)$ & $-1.3(-3.3$ to 0.4$)$ & $<0.001$ & $\mathrm{NC}>\mathrm{AD}^{* * *}, \mathrm{NC}>\mathrm{PD}^{* *}, \mathrm{PD}>\mathrm{AD}^{* *}$ \\
\hline Recognition & $0.2(-2.4$ to 1.7$)$ & $-1.6(-4.5$ to 1.7$)$ & $-0.6(-3$ to 1.6$)$ & $<0.001$ & $\mathrm{NC}>\mathrm{AD}^{* * *}, \mathrm{PD}>\mathrm{AD} \mathrm{D}^{* *}, \mathrm{NC}=\mathrm{PD}$ \\
\hline
\end{tabular}

${ }^{a}$ p-Values for Kruskal-Wallis test.

${ }^{b} p$-Values for Mann-Whitney $U$ test.

${ }^{*} p<0.05,{ }^{*} p<0.01,{ }^{*}{ }^{*} p<0.001, "=$ " no significant difference. 
Table 3 | Global relative power and median frequencies (median and range)

\begin{tabular}{|c|c|c|c|c|c|}
\hline & NC & $A D^{a}$ & $\mathbf{P D}^{\mathrm{a}}$ & $p$-value ${ }^{a}$ & Sub-group comparisons ${ }^{b}$ \\
\hline Delta (1-4 Hz) & $19.5(6.1-40.7)$ & $19.4(7.5-32.9)$ & $20.4(7.6-37.0)$ & 0.59 & \\
\hline Theta $(4-8 \mathrm{~Hz})$ & $11.2(5.7-61.6)$ & $16.5(6.5-46.9)$ & $24.4(9.4-56.6)$ & 0.002 & $N C<A D^{\#}, N C<P D^{* *}, A D<P D^{*}$ \\
\hline Alpha2 (10-13 Hz) & $14.2(2.7-56.1)$ & $11.8(4.4-36.2)$ & $9.3(4.1-25)$ & 0.04 & $N C>P D^{* *}, A D=N C, A D=P D$ \\
\hline Beta $(13-30 \mathrm{~Hz})$ & $24.2(11.4-42.1)$ & $18.9(7.5-48.2)$ & $22.3(8.8-28.3)$ & 0.30 & \\
\hline
\end{tabular}

${ }^{a} p$-Values for ANOVA.

${ }^{b} p$-Values for t-tests.

${ }^{*} p<0.1,{ }^{*} p<0.05,{ }^{*} p<0.01,{ }^{* *} p<0.001, "="$ no significant difference.

A relative theta
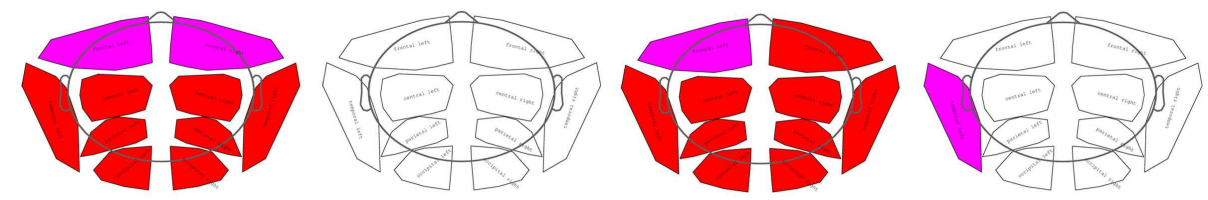

B relative alpha2

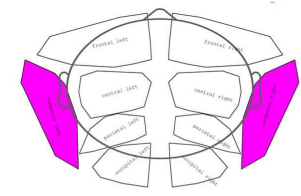

NC vs. AD vs. PD

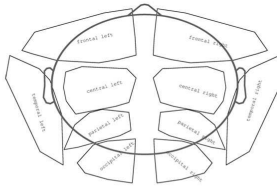

$A D$ vs. $P D$

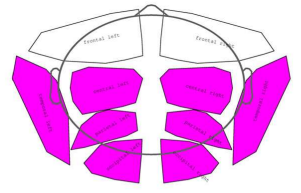

NC vs. PD

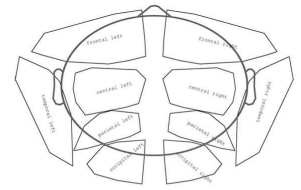

NC vs. AD

$$
\mathrm{p}<=.05 \bigcirc \mathrm{p}<=.01
$$

FIGURE 1 | Differences of regional band power between the three groups (NC, AD, and PD). (A) Relative theta power, (B) relative alpha2 power. (First column: ANOVA, second to forth columns: $t$-tests; pink: $p \leq 0.05$; red: $p \leq 0.01$; corrected for multiple comparison by permutation).

As the median frequency was significantly different between $\mathrm{AD}$ and $\mathrm{PD}$, it was chosen as independent variable for a logistic regression model to classify the two groups. A significant classification of both groups $(p=0.02)$ was achieved. After backwards elimination, the resulting model included only median frequency as predictor $(p=0.03)$. ROC analysis yielded an AUC of 0.72 with a sensitivity and specificity at the best index of Youden (0.45) of 60 and 85\%, respectively. The positive predictive and negative predictive values were 80 and $68 \%$, respectively.

\section{CONTROL ANALYSIS}

We checked for a confounding influence of the variables MMSE, LED, alertness, age, and gender on the power values, by entering the variables into linear models with stepwise backwards elimination. No significant effects of the potentially confounding variables on the qEEG parameters were found. We conducted sensitivity analysis by running the statistics on all but one PD patient taking neuroleptics and on all but three patients taking AChE-inhibitors. The outcome was not affected as similar results and significances were obtained with and without those patients.

\section{DISCUSSION}

The main alteration of EEG in patients with subtle cognitive deficits due to $\mathrm{AD}$ or $\mathrm{PD}$ consists in an increase of relative theta power, predominantly in the temporal regions and in a slowing of the occipital median frequency. The slowing is more pronounced in $\mathrm{PD}$ than in $\mathrm{AD}$ patients.

Bi-temporal increase of relative theta power in demented PD and $A D$ patients is a known finding (Babiloni et al., 2011). While in $\mathrm{PD}, \mathrm{EEG}$ slowing occurs already before cognitive decline (Berendse and Stam, 2007), it is observed in AD with incipient MCI (Roh et al., 2011).

Dysfunction of the cholinergic system is common in both, AD and PD (Mesulam et al., 2004; Bohnen and Albin, 2011) and an overlap of histopathological (Hughes et al., 1993; Emre, 2003) and biochemical changes (Alves et al., 2014) is known. EEG frequency is accelerated by cholinergic function and responds to therapy with acetylcholinesterase inhibitors in AD und PD (Fogelson et al., 2003; Babiloni et al., 2013). This fact could explain partly the slowing of EEG in both patient groups in our sample. Interestingly, EEG slowing is more pronounced in PD than in 
$\mathrm{AD}$ in the present study. This is in line and extends the findings by Babiloni et al. who found similar results $\mathrm{AD}$ and $\mathrm{PD}$ patients with more advanced cognitive dysfunction This difference may reflect a greater cholinergic deficit in cognitively impaired patients with PD-compared to AD (Bohnen et al., 2003; Kotagal et al., 2012) and reflects the degeneration of the cholinergic system as an important factor for cognitive decline in PD (Emre et al., 2004).

The advantage of the present study is the comparison of demographically well balanced groups of patients with $\mathrm{AD}$ or PD at incipient cognitive decline with a group of NCs. Limitations include the relatively small sample sizes and the inherent failure of AD-MCI patients to formally fulfill the diagnostic criteria of AD. Longitudinal assessment of these patients is warranted.

\section{ACKNOWLEDGMENTS}

We thank the participating subjects and caregivers. We appreciate Claudio Babiloni's valuable advice after review of the manuscript. The financial support of the Synapsis/Parrotia Foundation, Swiss National Science Foundation (grants: 33CM30_140338, 33CM30_124115; 326030-128775/1), Novartis Research Foundation, Freiwillige Akademische Gesellschaft Basel, Gottfried und Julia Bangerter-Rhyner Stiftung, Jacques und Gloria Gossweiler Foundation, Parkinson Schweiz, and the Mach-Gaensslen Foundation are gratefully acknowledged.

\section{REFERENCES}

Albert, M. S., DeKosky, S. T., Dickson, D., Dubois, B., Feldman, H. H., Fox, N. C., et al. (2011). The diagnosis of mild cognitive impairment due to Alzheimer's disease: recommendations from the national institute on aging-Alzheimer's association workgroups on diagnostic guidelines for Alzheimer's disease. Alzheimers Dement. 7, 270-279. doi:10.1016/j.jalz.2011.03.008

Alves, G., Lange, J., Blennow, K., Zetterberg, H., Andreasson, U., Forland, M. G., et al. (2014). CSF A 42 predicts early-onset dementia in Parkinson disease. Neurology. 82, 1784-1790. doi:10.1212/WNL.0000000000000425

Babiloni, C., De Pandis, M. F., Vecchio, F., Buffo, P., Sorpresi, F., Frisoni, G. B., et al. (2011). Cortical sources of resting state electroencephalographic rhythms in Parkinson's disease related dementia and Alzheimer's disease. Clin. Neurophysiol. 122, 2355-2364. doi:10.1016/j.clinph.2011.03.029

Babiloni, C., Del Percio, C., Bordet, R., Bourriez, J.-L., Bentivoglio, M., Payoux, P., et al. (2013). Effects of acetylcholinesterase inhibitors and memantine on resting-state electroencephalographic rhythms in Alzheimer's disease patients. Clin. Neurophysiol. 124, 837-850. doi:10.1016/j.clinph.2012.09.017

Bennys, K., Rondouin, G., Vergnes, C., and Touchon, J. (2001). Diagnostic value of quantitative EEG in Alzheimer's disease. Neurophysiol. Clin. 31, 153-160. doi:10.1016/S0987-7053(01)00254-4

Berendse, H. W., and Stam, C. J. (2007). Stage-dependent patterns of disturbed neural synchrony in Parkinson's disease. Parkinsonism Relat. Disord. 13, S440-S445. doi:10.1016/S1353-8020(08)70046-4

Berres, M., Monsch, A. U., Bernasconi, F., Thalmann, B., and Stähelin, H. B. (2000). Normal ranges of neuropsychological tests for the diagnosis of Alzheimer's disease. Stud. Health Technol. Inform. 77, 195-199.

Bohnen, N. I., and Albin, R. L. (2011). The cholinergic system and Parkinson disease. Behav. Brain Res. 221, 564-573. doi:10.1016/j.bbr.2009.12.048

Bohnen, N. I., Kaufer, D. I., Ivanco, L. S., Lopresti, B., Koeppe, R. A., Davis, J. G., et al. (2003). Cortical cholinergic function is more severely affected in parkinsonian dementia than in Alzheimer disease: an in vivo positron emission tomographic study. Arch. Neurol. 60, 1745-1748. doi:10.1001/archneur.60. 12.1745

Bousleiman, H., Zimmermann, R., Ahmed, S., Hardmeier, M., Hatz, F., Schindler, C., et al. (2014). Power spectra for screening parkinsonian patients for mild cognitive impairment. Annal. Clin. Transl. Neurol. doi:10.1002/acn3.129
Caviness, J. N., Hentz, J. G., Evidente, V. G., Driver-Dunckley, E., Samanta, J., Mahant, P., et al. (2007). Both early and late cognitive dysfunction affects the electroencephalogram in Parkinson's disease. Parkinsonism Relat. Disord. 13, 348-354. doi:10.1016/j.parkreldis.2007.01.003

Czigler, B., Csikós, D., Hidasi, Z., Anna Gaál, Z., Csibri, E., Kiss, E., et al. (2008). Quantitative EEG in early Alzheimer's disease patients - power spectrum and complexity features. Int. J. Psychophysiol. 68, 75-80. doi:10.1016/j.ijpsycho.2007. 11.002

Duara, R., Loewenstein, D. A., Greig, M. T., Potter, E., Barker, W., Raj, A., et al. (2011). Pre-MCI and MCI: neuropsychological, clinical, and imaging features and progression rates. Am. J. Geriatr. Psychiatry. 19, 951-960. doi:10.1097/JGP. 0b013e3182107c69

Duffy, F. H., McAnulty, G. B., and Albert, M. S. (1995). Temporoparietal electrophysiological differences characterize patients with Alzheimer's disease: a split-half replication study. Cereb. Cortex. 1991, 215-221. doi:10.1093/cercor/5.3.215

Emre, M. (2003). What causes mental dysfunction in Parkinson's disease? Mov. Disord. 18, 63-71. doi:10.1002/mds. 10565

Emre, M., Aarsland, D., Albanese, A., Byrne, E. J., Deuschl, G., De Deyn, P. P., et al. (2004). Rivastigmine for dementia associated with Parkinson's disease. N. Engl. J. Med. 351, 2509-2518. doi:10.1056/NEJMoa041470

Emre, M., Aarsland, D., Brown, R., Burn, D. J., Duyckaerts, C., Mizuno, Y., et al. (2007). Clinical diagnostic criteria for dementia associated with Parkinson's disease. Mov. Disord. 22, 1689-1707. doi:10.1002/mds.21507

Fogelson, N., Kogan, E., Korczyn, A. D., Giladi, N., Shabtai, H., and Neufeld, M. Y. (2003). Effects of rivastigmine on the quantitative EEG in demented parkinsonian patients. Acta Neurol. Scand. 107, 252-255. doi:10.1034/j.1600-0404.2003. 00081.x

Folstein, M. F., Folstein, S. E., and McHugh, P. R. (1975). "Mini-mental state"?: a practical method for grading the cognitive state of patients for the clinician. $J$. Psychiatr. Res. 12, 189-198. doi:10.1016/0022-3956(75)90026-6

Fonseca, L. C., Tedrus, G. M. A. S., Carvas, P. N., and Machado, E. C. F. A. (2013). Comparison of quantitative EEG between patients with Alzheimer's disease and those with Parkinson's disease dementia. Clin. Neurophysiol. 124, 1970-1974. doi:10.1016/j.clinph.2013.05.001

Fonseca, L. C., Tedrus, G. M. A. S., Letro, G. H., and Bossoni, A. S. (2009). Dementia, mild cognitive impairment and quantitative EEG in patients with Parkinson's disease. Clin. EEG Neurosci. 40, 168-172. doi:10.1177/155005940904000309

Gasser, T., Bächer, P., and Möcks, J. (1982). Transformations towards the normal distribution of broad band spectral parameters of the EEG. Electroencephalogr. Clin. Neurophysiol. 53, 119-124. doi:10.1016/0013-4694(82)90112-2

Hatz, F., Benz, N., Hardmeier, M., Zimmermann, R., Rueegg, S., Schindler, C., et al. (2013). Quantitative EEG and apolipoprotein E-genotype improve classification of patients with suspected Alzheimer's disease. Clin. Neurophysiol. 124, 2146-2152. doi:10.1016/j.clinph.2013.04.339

Hatz, F., Hardmeier, M., Bousleiman, H., Rüeeg, S., Schindler, C., and Fuhr, P. (2014). Reliability of fully automated versus visually controlled pre- and post-processing of resting-state EEG. Clin. Neurophysiol. doi:10.1016/j.clinph.2014.05.014

Hughes, A. J., Daniel, S. E., Blankson, S., and Lees, A. J. (1993). A clinicopathologic study of 100 cases of Parkinson's disease. Arch. Neurol. 50, 140-148. doi:10.1001/archneur.1993.00540020018011

Janvin, C. C., Larsen, J. P., Aarsland, D., and Hugdahl, K. (2006). Subtypes of mild cognitive impairment in Parkinson's disease: progression to dementia. Mov. Disord. 21, 1343-1349. doi:10.1002/mds.20974

Kotagal, V., Müller, M. L. T. M., Kaufer, D. I., Koeppe, R. A., and Bohnen, N. I. (2012). Thalamic cholinergic innervation is spared in Alzheimer disease compared to parkinsonian disorders. Neurosci. Lett. 514, 169-172. doi:10.1016/j.neulet.2012. 02.083

Litvan, I., Goldman, J. G., Tröster, A. I., Schmand, B. A., Weintraub, D., Petersen, R. C., et al. (2012). Diagnostic criteria for mild cognitive impairment in Parkinson's disease: movement disorder society task force guidelines. Mov. Disord. 27, 349-356. doi:10.1002/mds.24893

McKhann, G., Drachman, D., Folstein, M. F., Katzman, R., Price, D., and Stadlan, E. M. (1984). Clinical diagnosis of Alzheimer's disease: report of the NINCDS-ADRDA work group under the auspices of department of health and human services task force on Alzheimer's disease. Neurology. 34, 939-944. doi:10.1212/WNL.34.7.939

Mesulam, M., Shaw, P., Mash, D., and Weintraub, S. (2004). Cholinergic nucleus basalis tauopathy emerges early in the aging-MCI-AD continuum. Ann. Neurol. 55, 815-828. doi:10.1002/ana.20100 
Nichols, T. E., and Holmes, A. P. (2002). Nonparametric permutation tests for functional neuroimaging: a primer with examples. Hum. Brain Mapp. 15, 1-25. doi:10.1002/hbm.1058

Panza, F., Frisardi, V., Solfrizzi, V., Imbimbo, B. P., Logroscino, G., Santamato, A., et al. (2012). Immunotherapy for Alzheimer's disease: from anti- $\beta$-amyloid to tau-based immunization strategies. Immunotherapy. 4, 213-238. doi:10.2217/ imt.11.170

Penttilä, M., Partanen, J. V., Soininen, H., and Riekkinen, P. J. (1985). Quantitative analysis of occipital EEG in different stages of Alzheimer's disease. Electroencephalogr. Clin. Neurophysiol. 60, 1-6. doi:10.1016/0013-4694(85) 90942-3

Ritchie, K., Artero, S., and Touchon, J. (2001). Classification criteria for mild cognitive impairment: a population-based validation study. Neurology. 56, 37-42. doi:10.1212/WNL.56.1.37

Roh, J. H., Park, M. H., Ko, D., Park, K.-W., Lee, D.-H., Han, C., et al. (2011). Region and frequency specific changes of spectral power in Alzheimer's disease and mild cognitive impairment. Clin. Neurophysiol. 122, 2169-2176. doi:10.1016/j.clinph.2011.03.023

Schmidtke, K., and Hermeneit, S. (2008). High rate of conversion to Alzheimer's disease in a cohort of amnestic MCI patients. Int. Psychogeriatr. 20, 96-108. doi:10.1017/S1041610207005509

Stoffers, D., Bosboom, J. L., Deijen, J. B., Wolters, E. C., Berendse, H. W., and Stam, C. J. (2007). Slowing of oscillatory brain activity is a stable characteristic of Parkinson's disease without dementia. Brain. 130, 1847-1860. doi:10.1093/brain/awm034

Thalmann, B., Spiegel, R., Stähelin, H., Brubacher, D., Ermini-Fünfschilling, D., Bläsi, S., et al. (2002). Dementia screening in general practice: optimised scoring for the clock drawing test. Brain Aging. 2, 36-43.

Winblad, B., Palmer, K., Kivipelto, M., Jelic, V., Fratiglioni, L., Wahlund, L. O., et al. (2004). Mild cognitive impairment; beyond controversies, towards a consensus: report of the international working group on mild cognitive impairment. J. Intern. Med. 256, 240-246. doi:10.1111/j.1365-2796.2004.01380.x

Conflict of Interest Statement: Nina Benz: none; Florian Hatz: none; Habib Bousleiman: none; Michael M. Ehrensperger: none; Ute Gschwandtner: Support from Mach-Gaensslen-Foundation, Gossweiler Foundation, Parkinson Schweiz, Synapsis Foundation, Botnar Foundation; Martin Hardmeier: none; Stephan Ruegg: Swiss National Science Foundation; Christian Schindler: Swiss National Science Foundation; Ronan Zimmermann: none; Andreas Urs Monsch: Swiss National Science Foundation, Parkinson Schweiz, Gossweiler Foundation, Synapsis Foundation, Novartis, Novartis Research Foundation; Peter Fuhr: Support of research from Swiss National Science Foundation, Mach-Gaensslen-Foundation, Gossweiler Foundation, Parkinson Schweiz, Synapsis Foundation, Botnar Foundation, Freiwillige Akademische Gesellschaft Basel, Novartis Research Foundation, Novartis, Roche, AbbVie.

Received: 17 July 2014; accepted: 24 October 2014; published online: 18 November 2014.

Citation: Benz N, Hatz F, Bousleiman H, Ehrensperger MM, Gschwandtner U, Hardmeier M, Ruegg S, Schindler C, Zimmermann R, Monsch AU and Fuhr P (2014) Slowing of EEG background activity in Parkinson's and Alzheimer's disease with early cognitive dysfunction. Front. Aging Neurosci. 6:314. doi: 10.3389/fnagi.2014.00314 This article was submitted to the journal Frontiers in Aging Neuroscience. Copyright (c) 2014 Benz, Hatz, Bousleiman, Ehrensperger, Gschwandtner, Hardmeier, Ruegg, Schindler, Zimmermann, Monsch and Fuhr. This is an open-access article distributed under the terms of the Creative Commons Attribution License (CC BY). The use, distribution or reproduction in other forums is permitted, provided the original author(s) or licensor are credited and that the original publication in this journal is cited, in accordance with accepted academic practice. No use, distribution or reproduction is permitted which does not comply with these terms. 